\title{
SÍNTESE E IMOBILIZAÇÃO DA LIPASE DE Rhizomucor miehei EM NANOPARTÍCULAS MAGNÉTICAS MODIFICADAS COM MOLÉCULAS DE LAURIL SULFATO
}

\author{
J. A. BORK ${ }^{1}$, R. O. HENRIQUES ${ }^{1}$, G. M. N. WEINSBERGER ${ }^{1}$, A. FURIGO Jr. ${ }^{1}$ \\ ${ }^{1}$ Universidade Federal de Santa Catarina, Departamento de Engenharia Química e Engenharia de \\ Alimentos \\ E-mail para contato: j.bork@ymail.com
}

\begin{abstract}
RESUMO - Nanopartículas magnéticas são térmica, química e biologicamente estáveis para em aplicações in vivo, motivando pesquisas para aplicação como suporte enzimático, uma vez que o núcleo magnético facilita a remoção destas do meio reacional e seu reuso. $\mathrm{O}$ suporte foi sintetizado por precipitação em meio alcalino contendo oxalato, sendo a seguir reagido com lauril sulfato de sódio (LS). A lipase de Rhizomucor miehei dissolvida em $\mathrm{NaCl}$ aquoso foi agitada por $24 \mathrm{~h}$ e o acompanhamento da imobilização mostrou que $57 \%$ foi imobilizada na primeira hora. A caracterização do suporte foi feita por espectrometria no infravermelho com transformada de Fourier (FTIR), mostrando redução dos picos do oxalato em 1390 e $1660 \mathrm{~cm}^{-1}$ e o aparecimento de picos de LS na região de $2900 \mathrm{~cm}^{-1}$. A imobilização da lipase foi evidenciada pelos picos em $1650 \mathrm{~cm}^{-1}$ atribuídos a ligações com proteínas. A atividade de esterificação foi medida com reação de ácido oleico e etanol usando $2 \%$ de enzima resultando em 27,57 U.mg ${ }^{-1}$ de atividade.
\end{abstract}

\section{INTRODUÇÃO}

Os óxidos metálicos como a magnetita $\left(\mathrm{Fe}_{3} \mathrm{O}_{4}\right)$ são alguns dos materiais mais explorados no campo da nanotecnologia (Maurício et al., 2013). O uso deste tipo de material tem como atrativo suas propriedades multifuncionais como biocompatibilidade, superparamagnetismo, baixa toxicidade e o pequeno tamanho das partículas (Ren et al., 2011). Assim, aplicações em áreas como na biomedicina, na farmácia (dispersão controlada de fármacos), em tecnologia enzimática (purificação e imobilização de proteínas), vêm sendo bastante exploradas (Jiang et al., 2009; Tran et al., 2012).

O uso da magnetita como suporte para imobilização de biocatalisadores se mostra favorável nesta área devido à elevada área superficial das nanopartículas em relação ao seu volume e o aumento da difusão e mobilidade das partículas, fatores estes que podem melhorar consideravelmente a eficiência catalítica da enzima imobilizada (Ansari e Husain, 2012). Adicionalmente, as magnetitas oferecem a facilidade de recuperação do catalisador através da aplicação de um campo magnético, o que pode minimizar o custo operacional do processo e também aumentar a pureza do produto (Jiang et al., 2009; Ren et al., 2011).

As magnetitas podem ser produzidas através de diversos processos. No entanto, a sua utilização como suportes para a imobilização de enzimas só é possível mediante uma modificação química ou física de sua estrutura. Esta modificação pode ser feita inserindo grupos funcionais 
hidrofílicos em sua superfície como aminas, hidroxilas e carboxilas, aumentando a afinidade das nanopartículas com a água. Esta propriedade permite a interação das nanopartículas com sistemas biológicos como enzimas, proteínas e aminoácidos (Maurício et al., 2013).

Desta forma, o objetivo deste trabalho foi desenvolver um suporte para a imobilização de enzimas que fosse térmica e quimicamente estável, apresentando assim uma versatilidade de aplicações em diferentes sistemas reacionais. A metodologia adotada baseou-se na síntese de magnetitas contento grupos oxalatos em sua superfície através de um processo de co-precipitação, seguindo da substituição dos oxalatos por sulfatos, permitindo assim a posterior imobilização da lipase de Rhizomucor miehei. A utilização do suporte sintetizado neste trabalho para fins de imobilização de enzimas ainda não foi retratado na literatura, conferindo a este estudo um caráter inédito.

\section{MATERIAL E MÉTODOS}

\subsection{Material}

Para este trabalho foi selecionada a lipase comercial de Rhizomucor miehei na forma livre, produzida pela Novozymes Latin América (Araucária, PR, Brasil), lauril sulfato de sódio, ácido oleico, hidróxido de sódio, palmitato de p-nitrofenila, etanol 98\%, corante azul brilhante de coomassie G-25, cloreto de sódio, oxalato de amônio, hidróxido de amônio $28 \%$, sulfato de ferro III, ácido fosfórico 85 \%, p-nitrofenol e carbonato de sódio, todos grau PA.

\subsection{Métodos}

Síntese da Magnetita (NSM-Ox): foram adicionados $11 \mathrm{~g}$ de $\mathrm{FeSO}_{4} \cdot 7 \mathrm{H}_{2} \mathrm{O}$ e $5,7 \mathrm{~g}$ de oxalato de amônio em quantidade suficiente de água livre de oxigênio até formar uma mistura homogênea amarela. Após, adicionou-se a esta solução $16 \mathrm{~g}$ de sulfato férrico, aquecendo até $75^{\circ} \mathrm{C}$. A seguir, corrigiu-se o $\mathrm{pH}$ com hidróxido de amônio concentrado até $\mathrm{pH}$ 9. A suspensão foi agitada durante $1 \mathrm{~h}$ à $75^{\circ} \mathrm{C}$ e posteriormente separou-se o sobrenadante das partículas com auxílio de uma barra magnética. Por fim, lavou-se as partículas primeiramente com água destilada e depois com três porções de etanol anidro, deixando-as secar em temperatura ambiente.

Funcionalização da Magnetita com Lauril Sulfato de Sódio (NSM-SDS): A funcionalização da magnetita foi feita preparando-se uma suspensão de partículas magnéticas na solução de lauril sulfato de sódio, selecionado em pH 5 na razão molar de $\mathrm{Fe}_{3} \mathrm{O}_{4}$ :lauril sulfato de 2:1 sob atmosfera de $\mathrm{N}_{2}$. A solução foi mantida sob agitação mecânica intensa por $24 \mathrm{~h}$ na temperatura de $75^{\circ} \mathrm{C}$. A seguir, as partículas foram lavadas com cinco porções de água desoxigenada quente $\left(60 \mathrm{a} 65^{\circ} \mathrm{C}\right) \mathrm{e}$ decantadas com auxílio de uma barra magnética, sendo colocadas em estufa a $40{ }^{\circ} \mathrm{C}$ até completa secagem.

Imobilização da Lipase Rhizomucor miehei (NSM-RM): Em $1 \mathrm{~g}$ de suporte foram adicionados $20 \mathrm{~mL}$ de uma solução de $\mathrm{NaCl}$ aquoso a $0,85 \%$, contendo a enzima solubilizada. A mistura foi agitada mecanicamente a $600 \mathrm{rpm}$ durante $24 \mathrm{~h}$. Após este tempo, as partículas foram decantadas com auxílio de uma barra magnética e lavadas com água destilada até o resíduo de lavagem não apresentar mais proteínas dissolvidas.O tempo mínimo de reação necessário para a imobilização da enzima no suporte magnético funcionalizado foi determinado a partir do acompanhamento do decréscimo do teor de proteínas presente no sobrenadante. Para isto, foram 
coletadas alíquotas de $100 \mu \mathrm{L}$ em determinados períodos de tempo e realizado a análise de proteínas de acordo com o método de Bradford.

Atividade hidrolítica: A atividade hidrolítica da lipase foi medida através da reação de hidrólise do palmitato de p-nitrofenila (p-NPP), segundo metodologia de Chiou e Wu (2004). A reação do p-NPP libera como produto o p-nitrofenol (p-NP), que absorve luz na região de $410 \mathrm{~nm}$. Para a reação, uma amostra de $0,1 \mathrm{~mL}$ de lipase livre ou $200 \mathrm{mg}$ do derivado enzimático foi adicionada a $1 \mathrm{~mL}$ de solução de p-NPP em etanol $0,5 \%(\mathrm{~m} / \mathrm{v})$ e $1 \mathrm{~mL}$ de solução tampão fosfato $0,05 \mathrm{M}$ (pH 7,0). Após encubação por $5 \mathrm{~min}$ a $30^{\circ} \mathrm{C}$, adicionou-se $2 \mathrm{~mL}$ de solução de carbonato de sódio $0,5 \mathrm{~N}$, seguido por centrifugação durante $10 \mathrm{~min}$ a $3.500 \mathrm{rpm}$. A absorvância foi medida a $410 \mathrm{~nm}$ em um espectrofotômetro UV/VIS (Hitachi modelo U-2900). Uma unidade (U) de atividade enzimática de hidrólise foi definida como a quantidade de enzima que catalisa a produção de $1 \mu \mathrm{mol}$ de $\mathrm{p}$-NP por minuto sob as condições experimentais.

Atividade de esterificação: A atividade de esterificação foi quantificada através do consumo de ácido oleico na reação entre o ácido oleico e o etanol com razão molar ácido:álcool de 1:1, à temperatura de $45{ }^{\circ} \mathrm{C}$. A reação foi acompanhada por $50 \mathrm{~min}$ iniciados a partir da adição do derivado enzimático $(2 \% \mathrm{~m} / \mathrm{m})$ ao meio reacional. A quantidade de ácido oleico consumido foi determinada por titulação com $\mathrm{NaOH} 0,2 \mathrm{~N}$ utilizando fenoftaleína como indicador. Uma unidade de atividade de esterificação foi definida como a quantidade de enzima que conduz ao consumo de $1 \mu \mathrm{mol}$ de ácido oleico por minuto nas condições experimentais descritas (Aguieira et al., 2011).

Determinação de proteínas totais: A determinação do teor de proteínas nas enzimas estudadas foi realizada pelo método de Bradford (1976), o qual consiste no aumento da absorvância na região de $595 \mathrm{~nm}$ causada pela concentração de proteínas na solução de corante Azul Brilhante de Coomassie G-25.

Espectroscopia no Infravermelho com Transformada de Fourier: Para identificação dos principais grupamentos funcionais bem como as ligações presentes nos compostos sintetizados, foram realizadas análises de Espectroscopia no Infravermelho por Transformada de Fourier (FTIR) em equipamento Perkin Elmer modelo FTIR 1760X.

Microscopia eletrônica de varredura (MEV): As análises de imagens por microscopia eletrônica (MEV-FEG) foram realizadas em equipamento JEOL modelo JSM-6390LV.

Análise Termogravimétrica: Foram realizadas análises termogravimétricas (TG) para acompanhar o perfil de perda mássica, e análise térmica diferencial (DTA) para o conhecimento do perfil térmico da amostra ao longo do seu aquecimento, ambos em equipamento Shimadzu modelo DTG-60. Os suportes com e sem enzima foram submetidos à combustão em atmosfera de ar sintético em rampa de temperatura ambiente até $900^{\circ} \mathrm{C}$ com taxa de aquecimento de $20^{\circ} \mathrm{C}$. min ${ }^{1}$ e vazão de gás de arraste de $100 \mathrm{~mL} \cdot \mathrm{min}^{-1}$.

\section{RESULTADOS}

Caracterização superficial do suporte enzimático: A Figura 1 apresenta o resultado das análises de FTIR dos suportes sintetizados na ausência e presença da enzima imobilizada. 


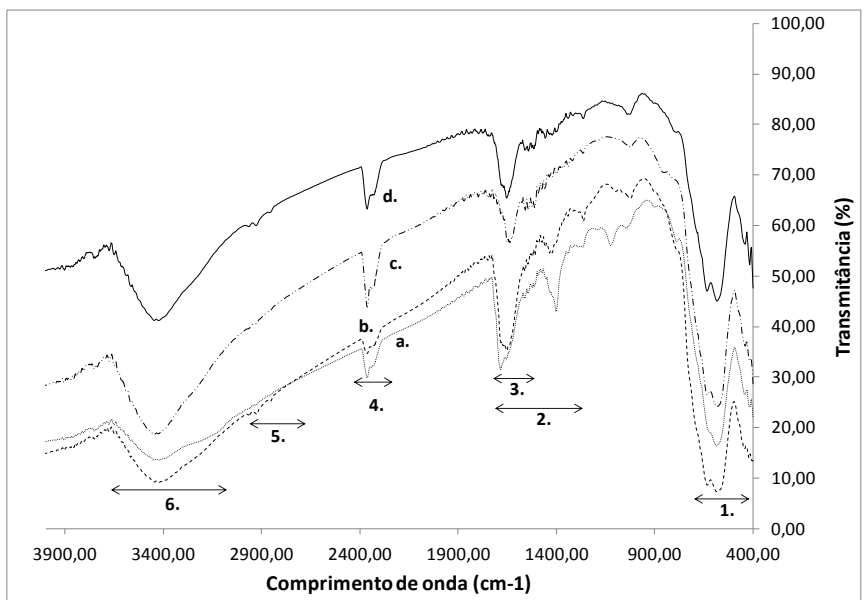

Figura 1 - Comparação dos espectros de infravermelho dos compostos sintetizados - NSM$\mathrm{Ox}(\mathrm{a}) ; \mathrm{NSM}-\mathrm{SDS}$ (b); $\mathrm{Fe}_{3} \mathrm{O}_{4}$ (c) e NSM-RM (d).

Os picos da região 1 entre 560 e $590 \mathrm{~cm}^{-1}$ são referentes ao estiramento da ligação $\mathrm{Fe}-\mathrm{O}$. Na região 2 o primeiro pico se refere aos estiramentos das moléculas de $\mathrm{CO}_{2}$ presentes nas moléculas do suporte, especialmente em NSM-Ox e NSM-SDS. Porém, é nesta mesma região que se encontram as evidências necessárias para a identificação qualitativa das proteínas adsorvidas no suporte. No segundo pico da região 2, destacado pela região 3, pode-se perceber que ocorre um suave deslocamento de banda de $1660 \mathrm{~cm}^{-1}$ para $1630 \mathrm{~cm}^{-1}$, apresentando outros picos secundários na região de $1410 \mathrm{~cm}^{-1}$, que indicam a presença de proteína adsorvida. As moléculas de água causam alguma interferência nesta mesma região, porém o deslocamento de banda é perceptível quando se comparam os espectros do suporte puro (b) com o do suporte contendo a enzima (d).

Os picos em destaque na região 2 estão localizados em uma zona conhecida como Amida I $\left(\sim 1650 \mathrm{~cm}^{-1}\right)$, e são atribuídos a amidas não substituídas. Deve ser salientado que, regularmente, os atributos da literatura indicam determinadas regiões de infravermelho em vez de uma posição de pico único a uma estrutura secundária característica de enzimas. Além disso, tem sido relatado que os segmentos com estruturas semelhantes, não apresentam necessariamente componentes de banda de frequências idênticas (Foresti et al., 2010).

A região 4, próximo a $2360 \mathrm{~cm}^{-1}$, presente em todas as amostras, corresponde ao movimento assimétrico de moléculas de $\mathrm{CO}_{2}$ adsorvidas na amostra, sendo este pico especialmente definido na amostra de magnetita pura, uma vez que esta foi preparada em condições fortemente alcalinas, o que favorece a reação com o $\mathrm{CO}_{2}$ atmosférico (Barbosa, 2007).

A região 5, de 2840 a $2960 \mathrm{~cm}^{-1}$, possível de ser observada nos espectros do suporte puro e contendo a enzima, corresponde as ligações do tipo $-\mathrm{CH}_{2}-$ do grupamento lauril inserido na partícula magnética e de alguma forma intensificado pelos grupos apolares presentes nas moléculas das enzimas imobilizadas (Barbosa, 2007).

Por fim, a região 6 formada por uma banda com ponto de máxima em torno de $3440 \mathrm{~cm}^{-1}$ corresponde à região que poderia ser atribuída aos aminoácidos terminais presentes na enzima, uma vez que esta região se intensifica para a região contendo as enzimas imobilizadas. Porém, é nesta mesma região que as moléculas de água têm sua maior absorção no infravermelho, sendo 
bastante intensa para a amostra de magnetita pura, não servindo, portanto, esta região de referencial para a análise qualitativa da imobilização (Barbosa, 2007).

As Figuras 2a e 2b mostram as imagens obtidas através de MEV com ampliação de $5000 \mathrm{X}$ do suporte com e sem enzima, respectivamente. A análise de superfície permite observar que na Figura $2 \mathrm{~b}$ ocorre o surgimento de particulados amorfos ausentes na Figura 2a, indicando a imobilização das enzimas sobre o suporte.

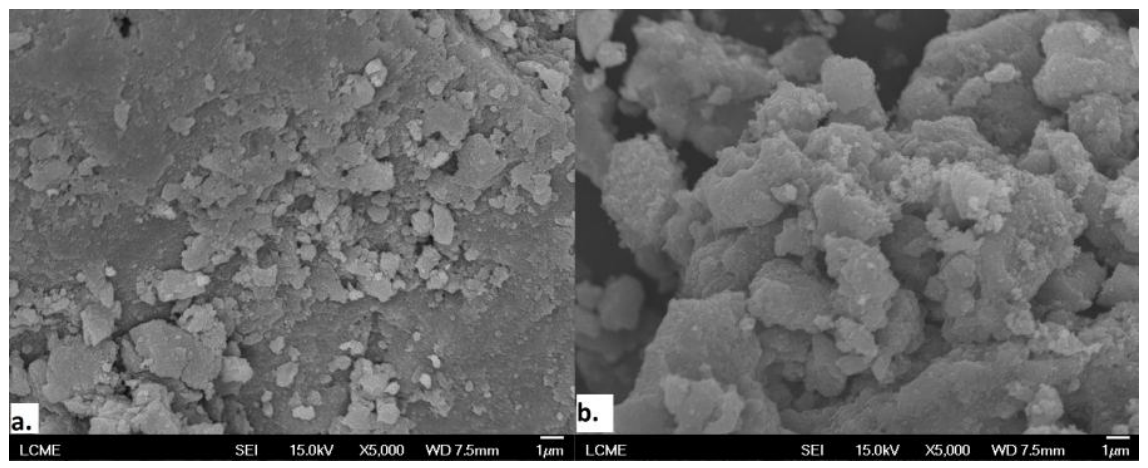

Figura 2 - Micrografia de MEV com ampliação de 5000 X do suporte sem a enzima (a) e com a enzima imobilizada (b).

Imobilização das enzimas no suporte funcionalizado: $\mathrm{O}$ grau de afinidade da enzima pelo suporte foi estudado através de isotermas envolvendo diferentes concentrações de enzimas ao longo do tempo. A Figura 3 mostra a curva de imobilização da lipase no suporte ao longo do tempo com os respectivos desvios padrão indicados no gráfico.

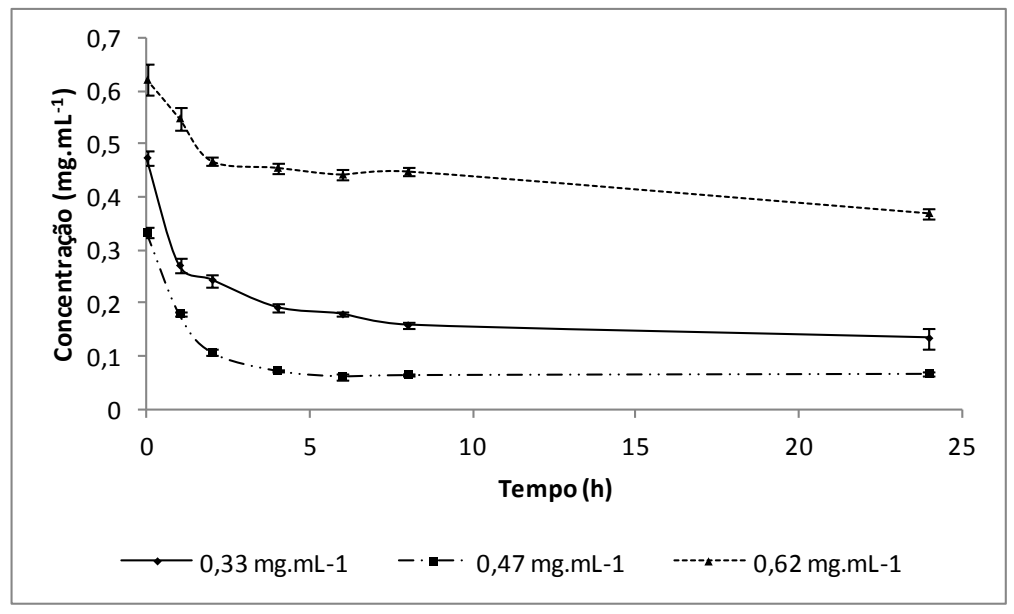

Figura 3 - Curva de imobilização das enzimas estudadas ao longo do tempo de contato do suporte com a enzima na forma solúvel, em diferentes concentrações iniciais.

A adsorção das enzimas ocorreu em dois regimes cinéticos distintos, tendo um aumento linear rápido da concentração na superfície até cerca de $1 \mathrm{~h}$ de imobilização, seguida de uma cinética mais lenta que atingiu o equilíbrio após 24 de agitação. O comportamento observado se compara ao descrito no trabalho de Foresti et al. (2010), no qual a enzima CALB foi imobilizada em suporte de $\mathrm{TiO}_{2}$ apresentando a rápida adsorção até $1 \mathrm{~h}$ de reação. Ainda segundo Foresti et al. (2010), este comportamento de adsorção das enzimas no suporte provavelmente segue o modo de 
adsorção sequencial aleatória, no qual a sequência de proteína adsorvente ocupa primeiramente a superfície da livre do suporte, e depois mais enzimas são adsorvidas com a formação de agregados (ligações cruzadas).

A medida de concentração de enzimas na solução foi feita através do uso do método de determinação de proteínas totais, e as concentrações estudadas apresentaram 0,33, 0,47 e $0,62 \mathrm{mg} \cdot \mathrm{mL}^{-1}$ de proteína dissolvida. A Tabela 1 mostra o comportamento da imobilização da enzima em diferentes concentrações.

Tabela 1- Resultado da imobilização da enzima Rhizomucor miehei no suporte sintetizado em termos de concentração mássica e percentual.

\begin{tabular}{ccc}
\hline Concentração de enzima inicial $\left(\mathrm{mg} \cdot \mathrm{mL}^{-1}\right)$ & Imobilização $\left(\mathrm{mg} / \mathrm{g}_{\text {suporte }}\right)$ & Imobilização $(\%)$ \\
\hline 0,33 & 5,4 & 80,00 \\
0,47 & 6,8 & 71,82 \\
0,62 & 5,0 & 40,47 \\
\hline
\end{tabular}

Ao usar a concentração de $0,33 \mathrm{mg} \cdot \mathrm{mL}^{-1}$ ocorreu o maior percentual de imobilização da enzima. No entanto, ao usar $0,47 \mathrm{mg} \cdot \mathrm{mL}^{-1}$ ocorreu a imobilização da maior massa de enzima por grama de suporte utilizado, sendo esta, então, a concentração selecionada para o preparo da enzima imobilizada no suporte desenvolvido neste trabalho. Para a concentração de $0,62 \mathrm{mg} \cdot \mathrm{mL}^{-1}$ verificou-se um decréscimo acentuado na quantidade de enzima imobilizada, uma vez que devido a sua alta concentração e força iônica, a mesma sofreu maior influência do mecanismo de precipitação por ligação cruzada do que a adsorção física, o que não é desejável, uma vez que para o reuso este suporte é sequencialmente lavado, removendo assim todo o conteúdo que não estiver ligado fisicamente ao suporte.

Atividade enzimática: A atividade enzimática de hidrólise da enzima imobilizada foi de $1,18 \mathrm{U}_{\mathrm{g}} \mathrm{g}^{-1}$ e a atividade de esterificação foi de $27,57 \mathrm{U} \cdot \mathrm{g}^{-1}$, considerando as condições acima especificadas para a unidade e o grama de derivado enzimático corresponde à soma da enzima mais o suporte.

Análise termogravimétrica: A Figura 4a mostra o resultado da análise termogravimétrica de NSM-Ox (a), NSM-SDS (b) e NSM-RM (c). O termograma pode ser dividido em três regiões principais. A região I corresponde a zona de perda de massa por perda de umidade superficial e umidade ligada, compreendida entre 25 e $145^{\circ} \mathrm{C}$. Nesta mesma região ainda pode-se notar a formação de um patamar que corresponde à região de transição da magnetita para a maghemita, o que faz com que ocorra um leve ganho de massa devido à oxidação do ferro II, constituinte da magnetita, para ferro III da maghemita. A região II, de 145 a $355^{\circ} \mathrm{C}$ corresponde à zona de oxidação da matéria carbônica ligada as partículas magnéticas, sejam estas o oxalato (a), o lauril sulfato (b) e a enzima palatase (c). A região III, de 355 a $900{ }^{\circ} \mathrm{C}$ corresponde à zona de oxidação de algum carbono residual que não tenha sido oxidado na região II e nesta região a maghemita passa da fase $\gamma-\mathrm{Fe}_{2} \mathrm{O}_{3}$ para $\alpha-\mathrm{Fe}_{2} \mathrm{O}_{3}$ (comumente ocorrem as duas fases entre 500 e $700{ }^{\circ} \mathrm{C}$ (Sartoratto et al., 2007), ou seja, não ocorre variação de massa, apenas uma mudança na estrutura cristalina do material suporte. 
$\mathrm{Na}$ Tabela 2, encontra-se o percentual de perda de massa ocorrido em cada região referente a cada amostra analisada. Na Figura 4b é possível observar o resultado da análise termogravimétrica de NSM-Ox (a), NSM-SDS (b) e NSM-RM (c).

Tabela 2 - Perda de massa $(\Delta \mathrm{m})$ em cada região e para cada amostra

\begin{tabular}{lcccc}
\hline Amostra & Região I - $\Delta \mathrm{m}(\%)$ & Região II - $\Delta \mathrm{m}(\%)$ & Região III - $\Delta \mathrm{m}(\%)$ \\
\hline NSM-Ox & 3,03 & 1,36 & 1,03 \\
NSM-SDS & 2,84 & 2,68 & 1,44 \\
NSM-RM & 1,67 & 4,87 & 1,45 \\
\hline
\end{tabular}

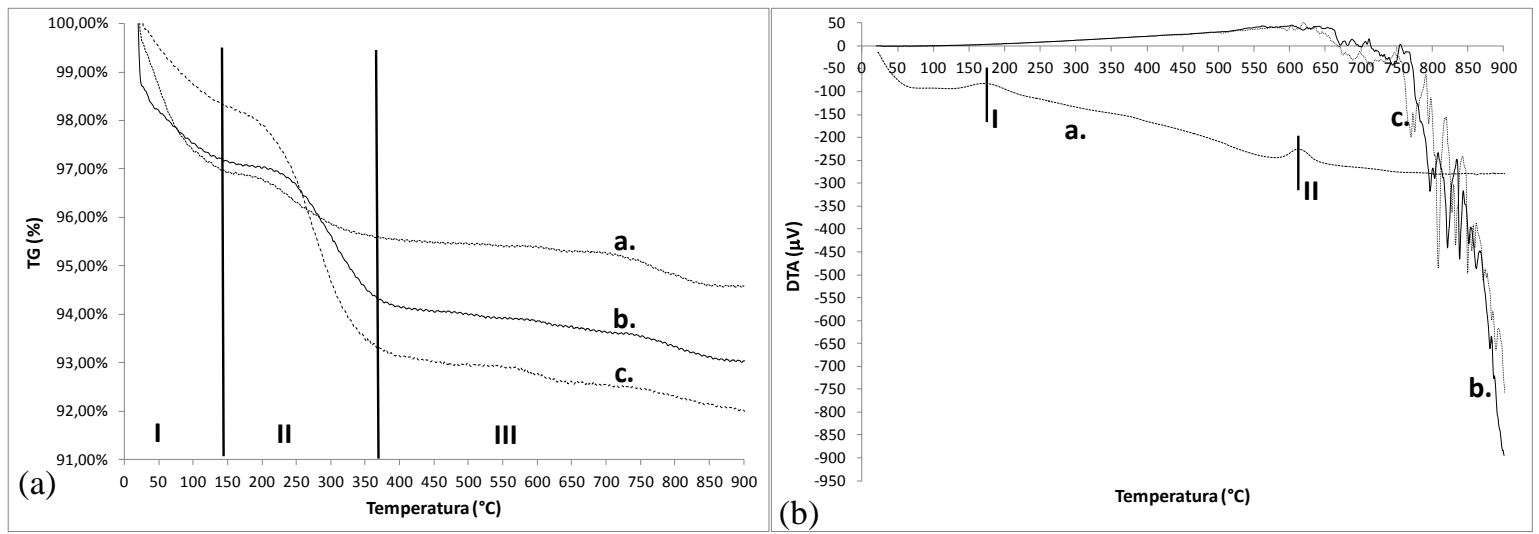

Figura 4 - (a) Análise termogravimétrica do suporte com e sem enzima - TG versus T. Taxa de aquecimento: $20{ }^{\circ} \mathrm{C} \cdot \mathrm{min}^{-1}$; temperatura final: $900{ }^{\circ} \mathrm{C}$; atmosfera: ar sintético. (b) Análise diferencial térmica (DTA) do suporte com e sem enzima - TG versus T. Taxa de aquecimento: $20{ }^{\circ} \mathrm{C} \cdot \mathrm{min}^{-1}$; Temperatura final: $900{ }^{\circ} \mathrm{C}$.

A análise diferencial térmica permite a melhor visualização dos eventos térmicos ocorridos durante a análise termogravimétrica. Na amostra NSM-Ox é possível identificar dois picos endotérmicos distintos, o primeiro (I) por volta de $170{ }^{\circ} \mathrm{C}$, confirma a temperatura de transição da magnetita para maghemita e a remoção da água ligada na superfície do material; e o segundo (II), por volta de $610{ }^{\circ} \mathrm{C}$, a transformação de $\gamma-\mathrm{Fe}_{2} \mathrm{O}_{3}$ para $\alpha-\mathrm{Fe}_{2} \mathrm{O}_{3}$ (hematita), a qual não possui propriedades magnéticas.

Conforme se pode constatar na figura acima, para as outras amostras não foi possível identificar claramente os eventos térmicos ocorridos, porém, vale destacar que estes somente começam a se intensificar após a temperatura de $650{ }^{\circ} \mathrm{C}$, ou seja, não são eventos relacionados às reações de decomposição da matéria orgânica presente no suporte. A ausência de eventos térmicos abaixo de $650{ }^{\circ} \mathrm{C}$ indica que não ocorreram rompimentos de ligações covalentes que eventualmente poderiam ter sido geradas durante o processo de imobilização, comprovando que o tipo de ligação da enzima com o suporte é puramente a adsorção física. Este comportamento também foi verificado no trabalho de Lee et al. (2009) no qual um suporte magnético contendo lauril sulfato foi usado para a imobilização da enzima porcina pancreática.

\section{CONCLUSÃO}


A partir dos resultados discutidos, podemos concluir que tanto a síntese da magnetita quanto a sua funcionalização com lauril sulfato de sódio foram efetivas, conforme demonstrado através das imagens de FTIR e MEV. O suporte sintetizado mostrou-se apto para o processo de imobilização da enzima de Rhizomucor miehei, sendo possível a imobilização de até $72 \%$ da massa de enzima em relação à massa de suporte. Estes resultados puderam ser confirmados através das análises de TGA e DTA, que também demonstraram a estabilidade térmica do suporte contendo a enzima imobilizada, o que o torna apto para a utilização em processos biotecnológicos.

\section{REFERÊNCIAS}

AGUIEIRAS, E. C. G.; VELOSO, C. O.; BEVILAQUA, J. V.; ROSAS, D. O; DA SILVA, M. A. P.; LANGONE, M. A. P. Estolides Synthesis Catalyzed by Immobilized Lipases. Enzyme Research, v.72, p. 1-7, 2011.

ANSARI, S. A.; HUSSAIN, Q. Potential applications of enzymes immobilized on/in nano materials: A review. Biotechnology Advances, v.30, p. 512-523, 2012.

BARBOSA, L. C. A. Espectroscopia no Infravermelho na caracterização de compostos orgânicos. Viçosa: UFV, 2007.

BRADFORD, M. M. A Rapid and Sensitive Method for the Quantitation of Microgram Quantities of Protein Utilizing the Principle of Protein-Dye Binding. Analytical Biochemistry, v. 72, p. 248-254, 1976.

CHIOU, S. H.; WU, W. T. Immobilization of Candida rugosa lipase on chitosan with activation of the hydroxyl groups. Biomaterials, v. 25(2), p. 197-204, 2004.

FORESTI, M. L.; VALLE, G.; BONETTO, R.; FERREIRA, M. L.; BRIAND, L. E. FTIR, SEM and fractal dimension characterization of lipase B from Candida antarctica immobilized onto titania at selected conditions. Applied Surface Science, v. 256, p. 1624-1635, 2010.

JIANG, Y.; GUO, C.; XIA, H.; MAHMOOD, I.; LIU, C.; LIU, H. Magnetic nanoparticles supported ionic liquids for lipase immobilization:Enzyme activity in catalyzing esterification. Journal of Molecular Catalysis B: Enzymatic, v. 58 , p. 103-109, 2009.

LEE, D.-G.; PONVEL, K. M.; KIM, M.; HWANG, S.; AHN, I.-K.; LEE, C.-H. Immobilization of lipase on hydrophobic nano-sized magnetite particles. Journal of Molecular Catalysis B: Enzymatic, v. 57, p. 62-66, 2009.

MAURICIO, M. R.; BARROS, H. R.; GUILHERME, M. R.; RADOVANIC, E.; RUBIRA, A. F.; CARVALHO, G. M. Synthesis of highly hydrophilic magnetic nanoparticles of $\mathrm{Fe}_{3} \mathrm{O}_{4}$ for potential use in biologic systems. Colloids and Surfaces A: Physicochemical and Engineering Aspects, v. 417, p. 224-229, 2013.

REN, Y.; RIVERA, J. G.; HE, L.; KULKARNI, H.; LEE, D.; MESSERSMITH, P. B. Facile, high efficiency immobilization of lipase enzyme on magnetic iron oxide nanoparticles via a biomimetic coating. BMC Biotechnology, v.11, n. 63, 2011.

SARTORATTO, P. P. C. et al. The thermal stability of maghemite-silica nanocomposites: An investigation using X-ray diffraction and Raman spectroscopy. Journal of Alloys and Compounds, v. 434-435, p. 650-654, 2007.

TRAN, D.; CHEN, C.; CHANG J. Immobilization of Burkholderia sp. lipase on a ferric silica nanocomposite for biodiesel production. Journal of Biotechnology,v.158 ,p. 12- 119, 2012. 